\title{
Language Learners' Internal Factors and Practical Applications: A Case of Vocabulary Learning Strategies
}

\author{
Mania Nosratinia, NazaninShakooriDivani, Alireza Zaker \\ Assistant Professor, Islamic Azad University at Central Tehran, Iran \\ MA in TEFL, Islamic Azad University at Central Tehran, Iran \\ MA in TEFL, Islamic Azad University at Central Tehran, Iran
}

\begin{abstract}
This study aimed to investigate the relationship among EFL learners' Autonomy (AU), Critical Thinking (CT), Personality Type (PT), and use of Vocabulary Learning Strategies (VLS). To fulfill this objective, 140 randomly selectedEFLlearners were asked to fill out four pertinent questionnaires.After performing preliminary analyses to check the assumptions of linear correlation, the data were analyzed using Pearson's correlation coefficient the results of which revealed the existence of a statistically significant relationship betweenAU and CT,AU and overall use of VLS, among the components of VLS and AU,CTand overall use ofVLS, and among the components of VLS and CT. However, no significant relationship was observedbetween PTand other variables of concern.
\end{abstract}

Keywords: Autonomy, critical thinking, individual differences, personality type, vocabulary learning strategies

\section{Introduction}

The receptive and productive capacities in a language seem to be highly affected by the knowledge of vocabulary, the basic element of the lexicon, which plays a fundamental and crucial role in the field of second/foreign language learning and teaching (Decarrico, 2001; Hall, 2000; Hatch \& Brown, 1995; Maley, 1986; Schmitt 2000).Flower (2000) states, "Words are the most important things students must learn. Grammar is important, but vocabulary is much more important" (p. 5). According to McCarthy (1988), the amount of vocabulary one possesses forms the biggest part of meaning of any language.In other words, inadequacy in lexical knowledge may hinder students' proficiency development (Fan, 2003). It is a plain fact that there is no language without words which are the building-blocks of a language, either the mother tongue or a second language (Thornbury, 2002).

Even in a learner's mother tongue, there is an incessant learning of new words and new meanings for old words (Thornbury, 2002). However, the acquisition of a large number of vocabulary items may be considered as one of the most difficult and challenging aspects of learning a second language for most of the L2 learners (Meara, 1980, 1982; Read, 2000; Stoffer, 1995) which makes learning vocabulary a hard task for many learners(Catalan, 2003). Researchers have focused their attention on the need for second language learners to optimize their vocabulary knowledge (Schmitt, 2000; Singleton, 1999).Considering the learners' difficulties in learning new words, acquiring the meaning, using them correctly, storing, recalling, and expanding their vocabulary size, it seems that teaching Vocabulary Learning Strategies (VLS) is a useful way to help students in their vocabulary learning tasks (Fan, 2003; Hedge, 2000). VLS are defined as the "knowledge about the mechanisms (processes, strategies) used in order to learn vocabulary as well as steps or actions taken by students (a) to find out the meaning of unknown words, (b) to retain them in long-term memory, (c) to recall them at will, and (d) to use them in oral or written mode" (Catalan, 2003, p. 56).

The incorporation of VLS into language teaching has been suggested by language educators to improve the effectiveness of vocabulary learning by students and to expand students' vocabulary size (Fan, 2003; KojicSabo \&Lightbown, 1999; Nation, 2001, 2004; Nation \&Meara, 2002; Schmitt, 2000; Shen, 2004; Tsuchida, 2002). In line with the great importance of VLS, some other scholars such as O'Malley and Chamot (1990); Oxford (1990); Rubin (1987); and Williams and Burden (1997) point out that strategies are essential tools for developing communicative competence. It is also argued that using appropriate language learning strategies, including VLS, result in improved proficiency and greater self-confidence in students (Oxford, 1990).

The traditional curriculum designs have neglected the teaching of how to learn strategies, but instead focused on imparting knowledge and skills (Williams \& Burden, 1997). However, the importance of teaching and using strategies in second language acquisition is becoming more and more acknowledged (O'Malley \&Chamot, 1996) andit is widely accepted that more attempts are needed to be made in order to observe the interaction between different individual factors of language learners and the way VLSare employed. Many factors affect the process of language learning in general and learning of vocabulary in particular including cultural, situational, social, and personal factors (Little, 1995). However, it is now a common belief that specific 
attempts should be made to inspect the ways different learners with different personalitytypes (PTs) and cognitive features might learn and internalize new vocabularies (Oxford \&Crookall, 1990). Oxford (2001) believes that one of the aspects of learning style that is crucial for language learning is personality type (PT). Moreover, many scholars have emphasized the huge advantages of understanding PTs (Cotteral, 1995; Sharp, 2004).Accordingly, more scientific endeavours are needed to determine and identify how different types of learners (critical, autonomous, introvert, extrovert, thinking, sensing, etc.) employVLS. As a result, inspecting the interaction between learner types and the applied VLS seems to be crucial and well-justified (Pressley, 2000; Pressley, Brown, El-Dinary, \&Afflerbach, 1995).

Another determining factor pertinent to successful learning is learners' Autonomy (AU) as argued by Walters and Bozkurt (2009, p. 405). AU according to Scharle and Szabo(2000) is the freedom and ability to manage one's own affairs, which entails the right to make decisions as well. An autonomous person, according to Paul and Elder (2002), is not dependant on others for the direction and control of one's thinking. Some educators such as Benson (2003), Dam (1995), Dickinson (1992),Holec (1981), and Little (1991) attached great importance to the necessity of AU in education.Holec (1981) defines an autonomouslearner as a "self-directed or autonomous learnerhaving, and holding, the responsibility for all the decisions concerning all aspects of learning" (p. 78). It presupposes learners' readiness to take control over their own learning which means that they initiate and manage their own learning, set their own priorities, and attempt to control psychological factors that influence their learning (Benson, 2001).

AU is a multidimensional capacity that will take different forms for different individuals and even for the same individual in different contexts or at different times (Benson, 2001).Promoting the development of learner $\mathrm{AU}$ in second language classes requires maximizing learners' potential for learning through critical reflection (Paul, 1990). Students must go beyond absorbing knowledge and learn to heighten skills to judge information, evaluate alternative evidence and argue with tenable reasons $(\mathrm{Ku}, 2009)$. Moreover, as Wagner (1997) argues, no one can develop expertise in any area without engaging in the effortful processes of thinking. Therefore, it seems that in order to develop the potential for learning via critical reflection learners need Critical Thinking (CT) and CT instruction which is recognized as an important competence for students to acquire in academic language (Connolly, 2000; Davidson, 1998; Davidson \& Dunham, 1997).CT, according to Astleitner (2002) as a high level of cognitive function, "is a purposeful, self-regulatory judgement which results in interpretation, analysis, evaluation, and inference, as well as explanations of evidential, conceptual, methodological or contextual consideration upon which the judgement is based" (p. 53).

Regarding the above mentioned arguments and premises, the question that is raised is whether the discussed variables are associated in a systematic way. This issue intrigued the researchers of this study to attempt to investigate the relationship among EFL learners' CT, AU, VLS, and PT. Therefore, the following research questions were put forth:

$Q_{1}$ : Is there any statistically significant relationship between EFL learners' critical thinking and autonomy?

$Q_{2}$ : Is there any statistically significant relationship between EFL learners' critical thinking and choice of vocabulary learning strategies?

$Q_{3}:$ Is there any statistically significant relationship between EFL learners' autonomy and personality type?

$Q_{4}$ : Is there any statistically significant relationship between EFL learners' autonomy and choice of vocabulary learning strategies?

$Q_{5}:$ Is there any statistically significant relationship between EFL learners' personality type and choice of vocabulary learning strategies?

$Q_{6}:$ Is there any statistically significant relationship between EFL learners' personality type and critical thinking?

$Q_{7}$. Is there any statistically significant difference among EFL learners' autonomy, critical thinking, and personality type in predicting their use of vocabulary learning strategies?

\section{Participants}

\section{Method}

The participants of this study were 140 EFL sophomore and junior students ( 123 females, $88 \%$, and 17 males, $12 \%$ ), between the ages of 20 and 25 (mean age $=22$ years), who were randomly selected from among those majoring in English Language Translation and English Language Teaching at Shiraz Azad University. It should be mentioned that the initial number of the participants was 160; however, 20of them were excluded from the final data due to careless coding and incomplete answers which resulted in maintaining 140 of the participants as the actual participants of the study.

\section{Instrumentation}

The following instruments were utilized in this study:

1. A questionnaire of autonomy by Spratt, Humphreys, and Chan (2002); 
2. A questionnaire of critical thinking by Honey (2000);

3. The Myers Briggs Type Indicator (MBTI, form M) questionnaire by Myers and McCaulley(1985); \&

4. A Vocabulary Learning Strategies questionnaire by Schmitt (1997).

\section{Learner Autonomy Questionnaire}

To evaluate the participants' level of AU, a questionnaire of AU including 52 items was administered. The questionnaire was designed by Spratt, Humphreys, and Chan (2002) who state that the questionnaire design is strongly influenced by Holec's (1981) definition of AU; he defines AU as "the ability to take charge of one's own learning where to take charge of one's learning is to have and to hold the responsibility for all the decisions concerning all aspects of this learning"(as cited in Spratt et al., 2002, p. 249).

Holec according to Spratt et al. (2002) argues that ability and responsibility are functioning in five principal areas that are: "determining objectives; defining contents, and progressions; selecting methods and techniques to be used; monitoring the procedure of acquisition; and evaluating what has happened"(p. 249). All these notions of ability and responsibility are incorporated in the questionnaire. In this study the Persian version of this questionnaire that has been translated and validated by Fahim and Behdani (2011) was employed to make sure of the full comprehension of the questions by the participants.

The instrument has four sections. The first section (items 1 to 13) focuses on examining the students' views of their responsibilities and those of their teachers. The second section (items 14 to 24) explores the students' confidence in their ability to operate autonomously. The third section (item 25) aims to measure the levels of student motivation to learn English. The fourth section (items 26 to 52) investigates the students' practice of autonomous learning in the form of both inside and outside class activities.

Respondents were asked to indicate their answers in 20 minutes in a Likert scale, sequentially assigning values of 1,2,3,4, and 5 to options of "not at all", "a little", "some", "mainly", and "completely". In section one; counting 1 for "very poor" to 5 for "very good" in section two; setting 5 to 1 beside the first to the last choices in section three; and attributing values of 1,2,3, and 4 to options of "never", "rarely", "sometimes", and "often" in section four. In this regard, the result can vary from 52 to 233. It is self-evident that the higher the mark, the more autonomous the participant is. In a study conducted by Zaker (2013) on EFL learners, the reliability of this questionnaire was estimated to be 0.84 . In this study, the reliability of AU questionnaire was estimated to be 0.84 using the Cronbach's alpha coefficient which demonstrated a good degree of reliability (Vogt, 2007).

\section{Critical Thinking Questionnaire}

The Critical Thinking Questionnaire intends to explore what a person might or might not do when thinking critically about a subject. Developed by Honey (2000), the questionnaire aims at evaluating the three main skills of comprehension, analysis, and evaluation of the participants. This questionnaire is a Likert-type questionnaire with 30 items which allows researchers to investigate the learners' ability in note-taking, summarizing, questioning, paraphrasing, researching, inferencing, discussing, classifying, outlining, comparing and contrasting, distinguishing, synthesizing, inductive and deductive reasoning.

The participants are asked to rate the frequency of each category they use on a 5-point Likert scale, ranging from never ( 1 point), seldom ( 2 points), sometimes ( 3 points), often (4 points), to always ( 5 points); therefore, the participants' scores are calculated by adding the numbers of the scores. The ultimate score is computed in the possible range of 30 to150. The participants were allocated 20 minutes to complete the questionnaire. In this study the Persian version of this questionnaire was employed which has been translated and validated by Naeini (2005). In a study conducted by Zaker (2013) on EFL learners, the reliability of this questionnaire was estimated to be 0.81 using the Cronbach's alpha coefficient. In this study the reliability of CT questionnaire was estimated to be 0.87 using the Cronbach's alpha coefficient which demonstrated a fair degree of reliability.

\section{The Myers-Briggs Type Indicator (MBTI)}

The main objective of the MBTI is to identify basic personal preferences. This test posits four bipolar scales (Table 1) in which "an individual is assumed to have a preference on the one side or the other" (Ehrman, 1996, p. 97).

Table 1: Characteristics of the Four MBTI Scales

\begin{tabular}{|l|l|}
\hline Extroversion & Introversion \\
Outside world & Internal world \\
Action & Introspection \\
Interaction & Concentration \\
Gregarious & A few people at a time \\
Seeks to find stimulation & Seeks to manage or reduce stimulation \\
Impulsive & Analytic \\
Auditory & Visual \\
Talkative & Reflective and constrained \\
\hline
\end{tabular}




\begin{tabular}{|c|c|}
\hline Likes study groups & Likes to work alone \\
\hline Sensing & Intuition \\
\hline Relatively direct from five senses & $\overline{\text { Further processed before becoming conscious }}$ \\
\hline Physical world & Meaning \\
\hline Sequential & Random \\
\hline Experience & Inspiration \\
\hline Specifics & Generalization \\
\hline Detail & Big picture \\
\hline What is concrete & What is abstract \\
\hline Thinking & Feeling \\
\hline Head & Heart \\
\hline Seeking objectivity & Values subjectivity \\
\hline Logical & Values \\
\hline Truth & Tact \\
\hline Fair & Harmony \\
\hline Expresses criticism & Expresses appreciation \\
\hline Analytic & Global \\
\hline Cost beneficial & Like-dislike \\
\hline Judging & Perceiving \\
\hline Planned & $\overline{\text { Open-ended }}$ \\
\hline Closure & Flexibility \\
\hline Decisions & Random \\
\hline Sequential & Autonomy \\
\hline Conscientious & Process \\
\hline Product & Tolerance of ambiguity \\
\hline Seeks certainty & \\
\hline
\end{tabular}

The combination of the four bipolar scales will result in 16 personality types, summarized in the Table 2:

Table 2: The Sixteen Personality Types Resulting from the Four Bipolar Scales

\begin{tabular}{|c|c|c|c|}
\hline ISTJ & ISFJ & INFJ & INTJ \\
\hline ISTP & ISFP & INFP & INTP \\
\hline ESTP & ESFP & ENFP & ENTP \\
\hline ESTJ & ESFJ & ESFJ & ESTJ \\
\hline
\end{tabular}

Human beings naturally use one mode of operation within each category more easily and more frequently than using the other modes of operation, and the combination of the four preferences defines one'sPT (Ehrman, 1996). It should be noted that the MBTI has got different versions, and in this study, form M, the latest version of the MBTI, was utilized. It is a self- report, Likert scale questionnaire, and the participants are asked to answer 93 questions over eight kind personality types: Extrovert (E), Introvert (I); Feeling (F), Thinking (T); Perceiving (P), Judging (J); Intuition (I), and Sensing (S). Each question has two possible answers, yes or no. Each answer is of the value of one point, and the MBTI takes about 45 minutes to administer.

Based on the scores that students gained in each PT category, their type of personality was recognized. The PTs were decided according to four bipolar dimensions (E and I, S and N, T and F, J and P). For example, if participants got a higher score in E than in I, they were extrovert. The PTs of the participants were grouped and the dominant PT was decided. The reported internal consistency reliabilities of MBTI are acceptable for most adult samples. Test-retest reliabilities show consistency over time, and MBTI results are consistent with participant's self-estimates of type (Myers \&McCaulley, 1985).

This instrument is originally written in English; however, in this study, the Persian translation was employed to ensure the full comprehension of the questions. The validity of the Persian version of MBTI (Form M) has been investigated by Bahri (as cited in Mohammadi, 2009). He investigated the construct validity of the MBTI by running a factor analysis using Principal Component Analysis (PCA) and Principal Axis Factoring (PAF) techniques. The results indicated the extraction of four factors for the MBTI. He came to this conclusion that the results support what the MBTI developers claim that this questionnaire measures. The reliability of the Persian translation of MBTI has been investigated by Bahri (as cited in Mohammadi, 2009), and the results were as follows: $\mathrm{EI}=0.82 ; \mathrm{TF}=0.86 ; \mathrm{JP}=0.84$, and $\mathrm{NS}=0.65$.

Vocabulary Learning Strategies Questionnaire (VLSQ)

The 60-item VLSQ by Schmitt's (1997) taxonomy of VLS was used to investigate the VLS of the participants. Schmitt's taxonomy of VLS is one of the most comprehensive and practical taxonomies in the domain of L2 VLSwhich according to Catalan (2003) has several advantages over other tests like eliciting answers easily, good degree of reliability, and suitability for different participants with different ages and backgrounds. Schmitt's Taxonomy of VLS (1997) contains five categories that are, metacognitive, cognitive, memory, determination, and social. Table 3 represents the five categories mentioned. 
Table 3: Categories of Vocabulary Learning Strategies

\begin{tabular}{|c|c|c|c|}
\hline \multicolumn{4}{|c|}{ Strategy Group } \\
\hline \multicolumn{4}{|c|}{ Strategies for the Discovery of a New Word's Meaning } \\
\hline DET & Analyze part of speech DET World lists & DET & World lists \\
\hline DET & Analyze affixes and roots & DET & Flash cards \\
\hline DET & Check of L1 cognate & SOC & Ask teacher for an L1 translation \\
\hline DET & $\begin{array}{l}\text { Analyze any available pictures or } \\
\text { gestures }\end{array}$ & SOC & $\begin{array}{l}\text { Ask teacher for paraphrase or synonym of } \\
\text { new word }\end{array}$ \\
\hline DET & Guess from textual context & SOC & $\begin{array}{l}\text { Ask teacher for a sentence including the } \\
\text { new word }\end{array}$ \\
\hline DET & Bilingual dictionary & SOC & Ask classmates for meaning \\
\hline DET & Monolingual dictionary & $\mathrm{SOC}$ & $\begin{array}{l}\text { Discovery new meaning through group } \\
\text { work activity }\end{array}$ \\
\hline \multicolumn{4}{|c|}{ Strategies for Consolidating a Word Once It Has Been Encountered } \\
\hline $\mathrm{SOC}$ & $\begin{array}{l}\text { Study and practice meaning in a } \\
\text { group }\end{array}$ & MEM & Use Keyword Method \\
\hline SOC & $\begin{array}{l}\text { Teacher checks students' flash cards or } \\
\text { world lists } \\
\text { for accuracy }\end{array}$ & MEM & Affixes and roots (remembering) \\
\hline SOC & Interact with native-speakers & MEM & Part of speech (remembering) \\
\hline MEM & $\begin{array}{l}\text { Study word with a pictorial representation } \\
\text { of itsMeaning }\end{array}$ & MEM & Paraphrase the word's meaning \\
\hline MEM & Image word's meaning & MEM & Use cognates in study \\
\hline MEM & $\begin{array}{l}\text { Connect word to a personal } \\
\text { experience }\end{array}$ & MEM & Learn the words of an idiom together \\
\hline MEM & $\begin{array}{l}\text { Associate the word with its } \\
\text { coordinates }\end{array}$ & MEM & Use physical action when learning a word \\
\hline MEM & $\begin{array}{l}\text { Connect the word to its synonyms } \\
\text { and antonyms }\end{array}$ & MEM & Use semantic feature grids \\
\hline MEM & Use semantic maps & $\mathrm{COG}$ & Verbal repetition \\
\hline MEM & $\begin{array}{lll}\begin{array}{l}\text { Use "scales" } \\
\text { adjectives }\end{array} & \text { for gradable } \\
\end{array}$ & $\mathrm{COG}$ & Written repletion \\
\hline MEM & Peg Method & $\mathrm{COG}$ & Word lists \\
\hline MEM & Loci Method & $\mathrm{COG}$ & Flash cards \\
\hline MEM & $\begin{array}{l}\text { Group words together } \\
\text { to study them }\end{array}$ & $\mathrm{COG}$ & Take notes in class \\
\hline MEM & $\begin{array}{l}\text { Group words together spatially on } \\
\text { a page }\end{array}$ & $\mathrm{COG}$ & $\begin{array}{l}\text { Use the vocabulary section in your } \\
\text { textbook }\end{array}$ \\
\hline MEM & Use new word in sentence & $\mathrm{COG}$ & Listen to tape of word lists \\
\hline MEM & $\begin{array}{l}\text { Group words together within a } \\
\text { storyline }\end{array}$ & $\mathrm{COG}$ & Put English labels on physical objects \\
\hline MEM & Study the spelling of a word & $\mathrm{COG}$ & Keep a vocabulary notebook \\
\hline MEM & Study the sound of a word & MET & $\begin{array}{l}\text { Use English-language media (songs, } \\
\text { movies, newscasts, etc.) }\end{array}$ \\
\hline MEM & $\begin{array}{l}\text { Say new word aloud when } \\
\text { studying }\end{array}$ & MET & Testing oneself with word tests \\
\hline MEM & Image word form & MET & Use spaced word practice \\
\hline MEM & Underline initial letter of the word & MET & Skip or pass new word \\
\hline MEM & Configuration & MET & Continue to study word over time \\
\hline
\end{tabular}

In this study, the Persian version of this questionnaire by Fahim\&Komijani (2010) was employed in order to make sure of the full comprehension of the participants. The participants were asked to rate the frequency of each category they use on a 5-point Liker scale, ranging from never (1 point), seldom (2 points), sometimes ( 3 points), often ( 4 points), to always ( 5 points). The time allocated for the completion of the questionnaire is 35 minutes, and the scores are ranged within 60 to 300 . The reliability of the VLSQ in this study was 0.92 , using Cronbach's alpha coefficient.

\section{Procedure}

In order to achieve the purpose of this study, the following procedure was carried out:

At the outset, one hundred and sixty participants were selected randomly from among both male and female EFL sophomore, and junior students, majoring in English Language Translation and English Language Teaching at Shiraz Islamic Azad University. Due to the nature of correlational study, no criterion for establishing homogeneity was adopted. Before administrating the questionnaires, the participants were fully briefed on the process of completing the questionnaires; this briefing was given by one of the researchers in 
Persian through explaining and exemplifying the process of answering the questions. One of the researchers was present while participants were responding to questionnaires to provide further explanations if required. In order to encourage the participants to answer with more care and honesty, they were assured that their responses would be used only for the purpose of this research and that the results would not be linked in any form to classroom evaluation.

Then, the participants were provided with the questionnaires. The learner AU and MBTI questionnaires were administered in one session, and the CT andVLSQ were administered in the subsequent session. Out of 160 students who took part in the main administration, some of them were excluded from data analysis due to careless coding, incomplete answers, and subject mortality bringing the final number of 140 participants. Out of 140,there were 17 males (12\%) and 123 females (88\%). The justification for the lower number of males as compared to females in this study is that female candidates commonly outnumber the opposite gender in the context of this study.

\section{Results}

In the present study, the data analysis provided descriptive statistics and inferential statistics as well. Descriptive statistics like mean, standard deviation, and standard error of the mean were obtained. Afterwards, to check the normality of distribution, the assumptions of linear correlation were checked.Moreover, the reliability of the research questionnaires was estimated through Cronbach's alpha coefficient. Regarding the inferential statistics, Pearson's product-moment correlation was used. Finally, a stepwise multiple regression analysis was applied to answer theseventh research question.

\section{Checking the Assumptions of Linear Correlation}

The present data were measured on an interval scale, and the participant's performance on the test was not affected by the performance of other participants; thence, they were independent. Moreover, to run a correlation the following assumptions should be checked:

1) Linear relation between each pair of variables.

2) Normality of distribution of each set of scores.

3) Homoscedasticity.

The assumptions were checked respectively to see whether running correlation was legitimate or not.

\section{Linear Relationship between Each Pair of Variables}

To check the linearity of relations, the researchers needed to visually inspect the data through creating scatter plots.As displayed in Figure 1, the relationship between CT and AU is linear. The spread of the dots shows a significant correlation between the two variables. The spread of the dots shows a moderate to high correlation between the two variables.

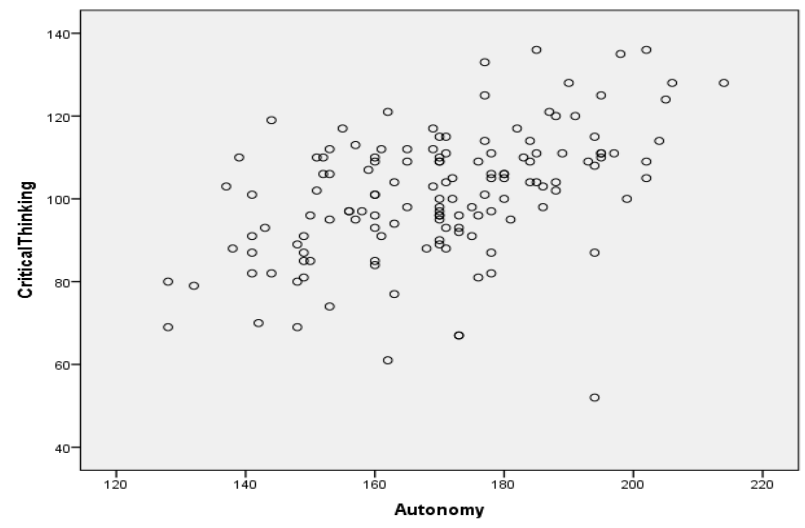

Figure 1: Linear Relationship between Autonomy and Critical Thinking

The relationship between CT and VLS, as shown in Figure 2, was also linear. The spread of the dots shows a significant correlation between the two variables. The spread of the dots shows a moderate to high correlation between the two variables. 


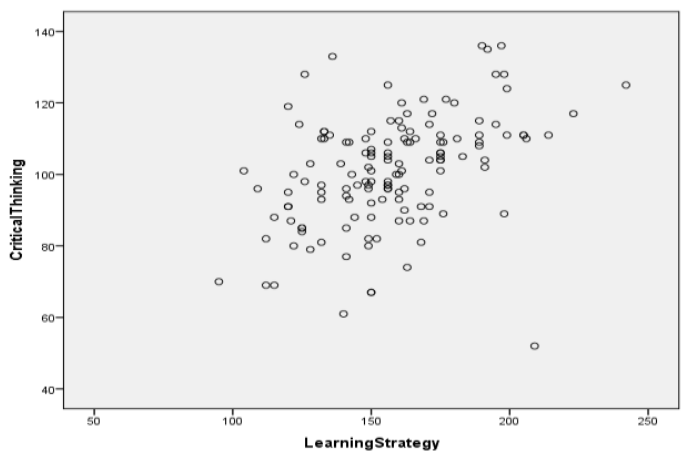

Figure 2: Linear Relationship between Critical Thinking and Vocabulary Learning Strategies

According to Figure 3, the relationship between AU and PT is not linear. The spread of the dots shows a weak correlation (almost zero) between the two variables.

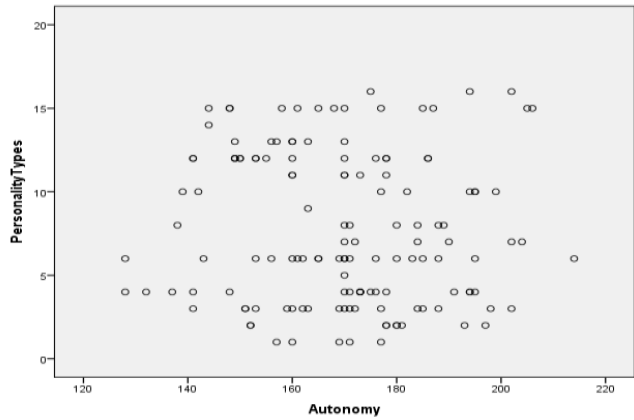

Figure 3: Linear Relationship between Autonomy and Personality Type

The relationship between AU and VLS, as shown in Figure 4, is linear. The spread of the dots shows a significant high correlation between the two variables.

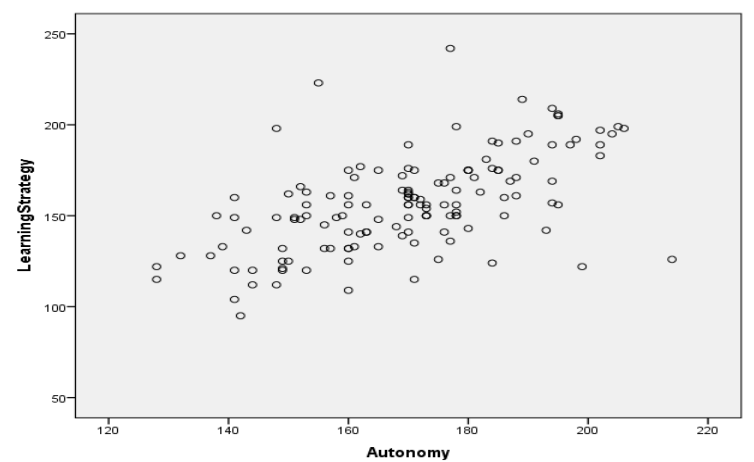

Figure 4: Linear Relationship between Autonomy and Vocabulary Learning Strategies

As displayed in Figure 5, the relationship between PT and VLS is not linear. The spread of the dots shows a weak correlation (almost zero) between the two variables. The rising-and-falling shape of the dots supports the non-linearity of the variables.

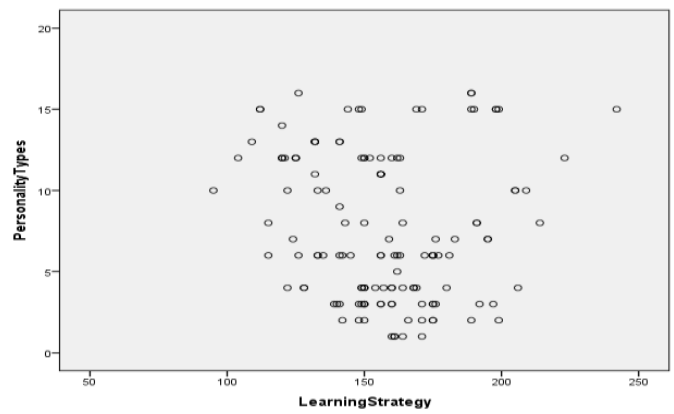

Figure 5: Linear Relationship between Personality Type and Vocabulary Learning Strategies 
Moreover, the relationship between CT and PT, as shown in Figure 6, was not linear. The spread of the dots shows a weak correlation between the two variables. The rising-and-falling shape of the dots supports the nonlinearity of the variables.

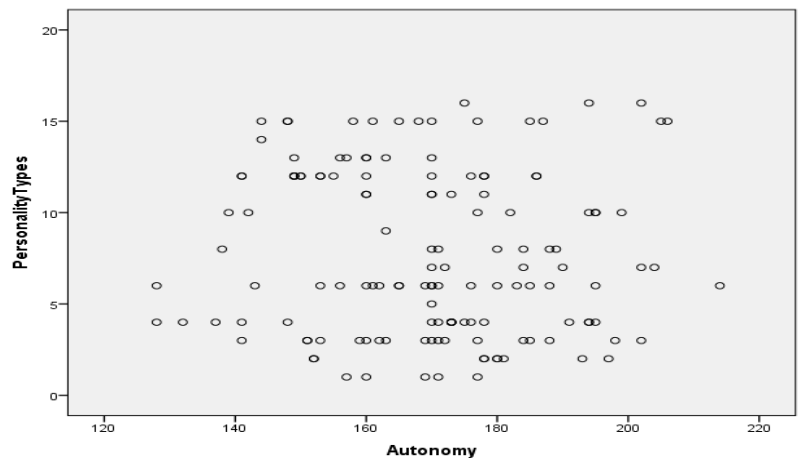

Figure 6: Linear Relationship between Personality Type and Critical Thinking

Normality of the Distribution of Each Set of Scores

To check the normality of the distributions, the descriptive statistics of the data were calculated separately for each variable. Moreover, the assumption of normality was tested through the skewness and kurtosis indices. As displayed in Table 4 the values of skewness and kurtosis are within the ranges of \pm 1.96 .

Table 4: Normality Assumptions

\begin{tabular}{|c|c|c|c|c|c|}
\hline \multirow{2}{*}{} & $\mathbf{N}$ & \multicolumn{2}{|c|}{ Skewness } & \multicolumn{2}{c|}{ Kurtosis } \\
\cline { 2 - 6 } & Statistic & Statistic & Std. Error & Statistic & Std. Error \\
\hline Learning Strategy & $\mathbf{1 4 0}$ & .330 & .205 & .154 & .407 \\
\hline Critical Thinking & 140 & -.330 & .205 & .465 & .407 \\
\hline Autonomy & 140 & -.025 & .205 & -.473 & .407 \\
\hline
\end{tabular}

It should be noted that PTwas not measured on an interval scale; therefore, the Spearman's correlation was run to probe a number of questions pertinent to this variable. The descriptive statistics of the data were calculated for each variable separately as follows:

Descriptive Statistics of the Vocabulary Learning Strategy Scores

Table 5 displays the descriptive statistics for the VLS. The mean, standard and variance for the VLSwere 157.14, 26.20, and 686.62 respectively. Furthermore, the K-R 21 reliability index was .92.

Table 5: Descriptive Statistics of Vocabulary Learning Strategy Scores

\begin{tabular}{|c|c|c|c|c|c|c|c|}
\hline & $\mathbf{N}$ & Minimum & Maximum & Mean & Std. Deviation & Variance & K-R21 \\
\hline Learning Strategy & $\mathbf{1 4 0}$ & $\mathbf{9 5}$ & $\mathbf{2 4 2}$ & $\mathbf{1 5 7 . 1 4}$ & $\mathbf{2 6 . 2 0 3}$ & $\mathbf{6 8 6 . 6 2 2}$ & $\mathbf{9 2}$ \\
\hline
\end{tabular}

Figure 7 displays the distribution of scores on the Vocabulary Learning Strategy.

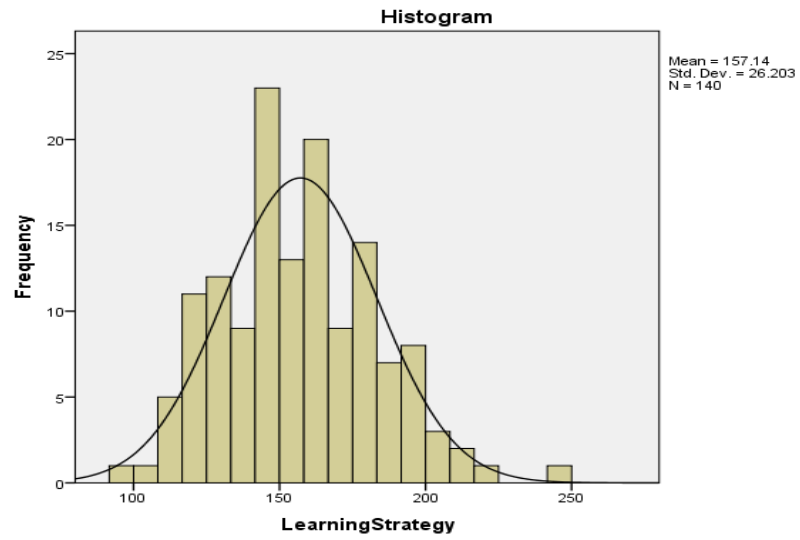

Figure 7: Distribution of Sores of Vocabulary Learning Strategy

Descriptive Statistics of the Critical Thinking Scores

Table 6 displays the descriptive statistics for the CT. The mean, standard and variance for the CTwere 101.04, 15.35, and 235.82 respectively. The K-R 21 reliability index was .87. Figure 8 displays the distribution of scores on $\mathrm{CT}$. 
Table 6: Descriptive Statistics of Critical Thinking Scores

\begin{tabular}{|c|c|c|c|c|c|c|c|}
\hline & $\mathbf{N}$ & Minimum & Maximum & Mean & Std. Deviation & Variance & K-R21 \\
\hline Critical Thinking & $\mathbf{1 4 0}$ & $\mathbf{5 2}$ & $\mathbf{1 3 6}$ & $\mathbf{1 0 1 . 0 4}$ & $\mathbf{1 5 . 3 5 7}$ & $\mathbf{2 3 5 . 8 2 5}$ & $\mathbf{. 8 7}$ \\
\hline
\end{tabular}

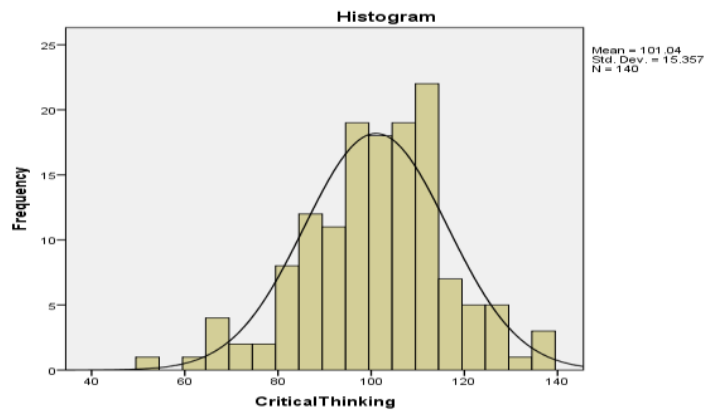

Figure 8: Distribution of Scores of the Critical Thinking

Descriptive Statistics of the Autonomy Scores

Table 7 displays the descriptive statistics for the AU scores. The mean, standard and variance for AUwere 169.87, 18.11, and 328.01 respectively. The K-R 21 reliability index was .84. Figure 9 displays the distribution of scores of the Autonomy.

Table 7: Descriptive Statistics of Autonomy Scores

\begin{tabular}{|c|c|c|c|c|c|c|c|}
\hline & $\mathbf{N}$ & Minimum & Maximum & Mean & Std. Deviation & Variance & K-R21 \\
\hline Autonomy & 140 & 128 & 214 & 169.87 & 18.111 & 328.012 & .84 \\
\hline
\end{tabular}

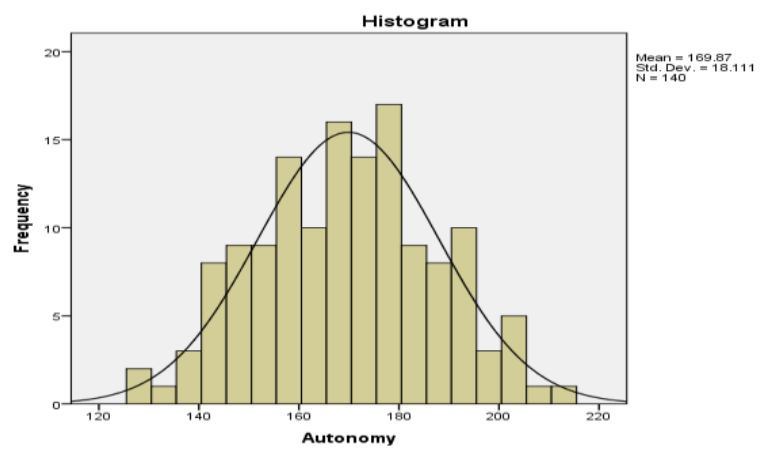

Figure 9: Distribution of Scores of Autonomy

Descriptive Statistics of the Personality Type Scores

MBTI questionnaire was another instrument used in the present study. According to Table 8, the PTs of the participants were determined and the frequency of each PT was computed.

Table 8: Distribution of the Different Personality Types and Their Frequency among the Participants

\begin{tabular}{|c|c|c|}
\hline PERSONALITY TYPE & FREQUENCY & PERCENTAGE \\
\hline ISTJ & 6 & $4.28 \%$ \\
ISTP & 2 & $4.42 \%$ \\
ESTP & 6 & $20.71 \%$ \\
ESTJ & 29 & $7.14 \%$ \\
ISFJ & 10 & $2.85 \%$ \\
ISFP & 4 & $3.57 \%$ \\
ESFP & 5 & $13.57 \%$ \\
ESFJ & 19 & $6.42 \%$ \\
INFJ & 9 & $1.42 \%$ \\
INFP & 2 & $4.28 \%$ \\
ENFP & 6 & $7.14 \%$ \\
ENFJ & 10 & $4.28 \%$ \\
INTJ & 6 & $1.42 \%$ \\
INTP & 2 & $2.85 \%$ \\
ENTP & 4 & $14.28 \%$ \\
\hline ENTJ & 20 & $100 \%$ \\
\hline I40 & 140 & \\
\hline
\end{tabular}


As Table 8 shows, the dominant PTwas ESTJ with the frequency of 29, followed by ENTJ (20) and ESFJ (19), ISFJ, ENFJ (each 10), INFJ (9), ISTJ, ESTP, ENFP, INTJ (each 6), ESFP (5), and ISFP, ENTP (each 4). Three types, ISTP, INFP, and INTP, had 2 representatives each, and all of the 16 personality types were present.

Descriptive Statistics of the Vocabulary Learning Strategy Components

The descriptive statistics related to the scores obtained from the components of VLSQ are presented in Table 9.

Table 9: Descriptive Statistics for Categories of VLSQ

\begin{tabular}{|c|c|c|c|c|c|c|}
\hline \multicolumn{7}{|c|}{ Descriptive Statistics } \\
\hline & $\mathrm{N}$ & Minimum & Maximum & $\mathrm{Me}$ & & Std. Deviation \\
\hline & Statistic & Statistic & Statistic & Statistic & $\begin{array}{c}\text { Std. } \\
\text { Error }\end{array}$ & Statistic \\
\hline Metacognitive & 140 & 9 & 23 & 72.10 & .313 & 3.133 \\
\hline Cognitive & 140 & 11 & 39 & 55.50 & .588 & 5.876 \\
\hline Memory & 140 & 43 & 111 & 28.92 & 1.587 & 15.870 \\
\hline Determination & 140 & 14 & 37 & 27.15 & .408 & 4.077 \\
\hline Social & 140 & 10 & 31 & 15.24 & .466 & 4.657 \\
\hline Valid N (list-wise) & 140 & & & & & \\
\hline
\end{tabular}

Also, as shown in Table 10, the assumption of normality wasmet, and the values of skewness and kurtosis were within the ranges of \pm 1.96 .

Table 10: Testing Normality Assumption of VLSQ Components

\begin{tabular}{|cccccc|}
\hline & $\mathbf{N}$ & \multicolumn{2}{c|}{ Skewness } & \multicolumn{2}{c|}{ Kurtosis } \\
\cline { 2 - 7 } & Statistic & Statistic & Std. Error & Statistic & Std. Error \\
\hline Metacognitive & 140 & .521 & .202 & -.598 & .401 \\
\hline Cognitive & 140 & .498 & .202 & -.231 & .401 \\
\hline Memory & 140 & .264 & .202 & -.508 & .401 \\
\hline Determination & 140 & -.138 & .202 & .528 & .401 \\
\hline Social & 140 & .856 & .202 & .175 & .401 \\
\hline Sum VLSQ & 140 & .298 & .202 & -.196 & .401 \\
\hline
\end{tabular}

\section{Homoscedasticity}

To check the assumption of homoscedasticity, that is, the assumption that variance of residuals for every pair of points on the independent variable is equal, the researcher examined the residuals plot (Figure 10).

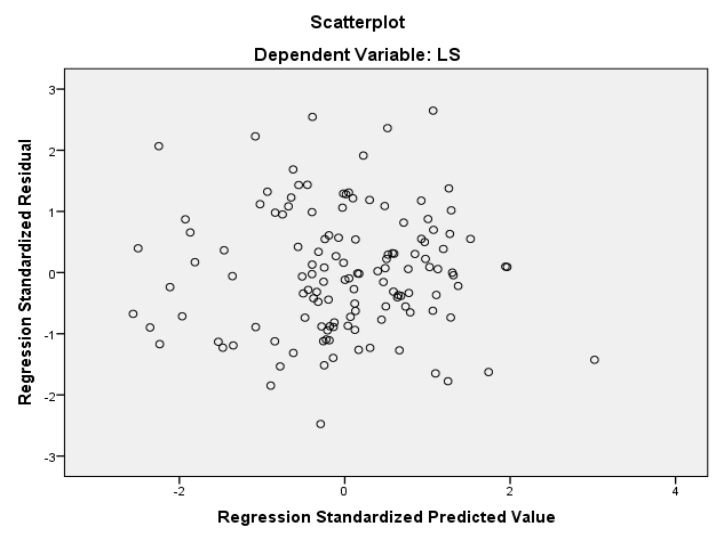

Figure 10: Plot of Studentized Residuals

As demonstrated in Figure 10, since the cloud of data was scattered randomly across the plot, the variance was homogeneous.

\section{The First research Question}

A Pearson's correlation was run to probe any significant relationship between AU of and CT among EFL learners. The results $\left(r_{138}=.78, p=.000<.05\right.$, it represents an almost large effect size) indicate a statistically significant relationship between the two variables (Table 11). Thus, there is a significant relationship between EFL learners' CT and AU. 
Table 11: Correlation between Autonomy and Critical Thinking

\begin{tabular}{|c|c|c|}
\hline \multicolumn{2}{|c|}{} & Autonomy \\
\hline \multirow{3}{*}{ Critical Thinking } & Pearson Correlation & .781 \\
\cline { 2 - 3 } & Sig. (2-tailed) & .000 \\
\cline { 2 - 3 } & $\mathrm{N}$ & $\mathbf{1 4 0}$ \\
\hline \multicolumn{2}{|c|}{$* *$ Correlation is significant at the 0.01 level (2-tailed). } \\
\hline
\end{tabular}

\section{The Second Research Question}

A Pearson's correlation was run to probe any significant relationship between VLS of EFL learners and their CT. The results $\left(r_{138}=.72, p=.000<.05\right.$, it represents a moderate to large effect size $)$ indicate a statistically significant relationship between the two variables (Table 12). Thus, there is asignificant relationship between EFL learners' CT and VLS.

Table 12: Correlation between Vocabulary Learning Strategy and Critical Thinking

\begin{tabular}{|l|c|c|}
\hline \multicolumn{2}{|c|}{} & Learning Strategy \\
\hline \multirow{3}{*}{ Critical Thinking } & Pearson Correlation &. $\mathbf{7 2 0}$ \\
\cline { 2 - 3 } & Sig. (2-tailed) & $\mathbf{. 0 0 0}$ \\
\cline { 2 - 3 } & $\mathbf{N}$ & $\mathbf{1 4 0}$ \\
\hline \multirow{2}{*}{$* *$ Correlation is significant at the 0.01 level (2-tailed). } \\
\hline
\end{tabular}

However, for further analysis, correlations between different components of VLSQ and CT were calculated (Table 13).

Table 13: Correlations between Each Component of VLSQ and Critical Thinking

\begin{tabular}{|c|c|c|}
\hline \multicolumn{3}{|c|}{ Correlations } \\
\hline VLSQ & & $\mathbf{C T}$ \\
\hline \multirow{3}{*}{ Metacognitive } & Pearson Correlation & $.798^{* *}$ \\
\hline & Sig. (2-tailed) & .08 \\
\hline & $\mathrm{N}$ & 140 \\
\hline \multirow{3}{*}{ Cognitive } & Pearson Correlation & $.614^{* *}$ \\
\hline & Sig. (2-tailed) & .002 \\
\hline & $\mathrm{N}$ & 140 \\
\hline \multirow{3}{*}{ Memory } & Pearson Correlation & $.609^{* *}$ \\
\hline & Sig. (2-tailed) & .03 \\
\hline & $\mathrm{N}$ & 140 \\
\hline \multirow{3}{*}{ Determination } & Pearson Correlation & $.521^{* *}$ \\
\hline & Sig. (2-tailed) & .09 \\
\hline & $\mathrm{N}$ & 140 \\
\hline \multirow{3}{*}{ Social } & Pearson Correlation & $.432^{* *}$ \\
\hline & Sig. (2-tailed) & .02 \\
\hline & $\mathrm{N}$ & 140 \\
\hline & gnificant at the 0.011 & \\
\hline
\end{tabular}

As Table 13 reveals,CT ability is correlated positively and significantly with all components of VLS.

\section{The Third Research Question}

A Spearman correlation was run to probe any significant relationship between AU of EFL learners and their PT. Before commenting on the findings, it should be mentioned that the relationship between the two variables is almost zero, as displayed in Figure 4. The results of the Spearman's correlation $\left(r_{138}=-.08, p=.30\right.$ $>.05$, it represents a weak effect size) indicated a non-significant relationship between the two variables (Table 14). Therefore, it was concluded that there is not any significant relationship between EFL learners' AU and PT.

Table 14: Correlation between Autonomy and Personality Type

\begin{tabular}{|l|c|c|}
\hline \multicolumn{2}{|c|}{} & Autonomy \\
\hline \multirow{3}{*}{ Personality Type } & Pearson Correlation & -.088 \\
\cline { 2 - 3 } & Sig. (2-tailed) & .300 \\
\cline { 2 - 3 } & $\mathbf{N}$ & 140 \\
\hline \multicolumn{2}{|c|}{. Correlation is significant at the 0.01 level (2-tailed). } \\
\hline
\end{tabular}

The Fourth Research Question

A Pearson's correlation was run to probe any significant relationship between VLS of EFL learners and their AU. The results of the Pearson's correlation $\left(r_{138}=.77, p=.000<.05\right.$, it represents a large effect size) indicate a statistically significant relationship between the two variables (Table 15). Thus, there wasa significant relationship between EFL learners' AU and VLS. 
Table 15: Correlation between Vocabulary Learning Strategy and Autonomy

\begin{tabular}{|c|c|c|}
\hline \multicolumn{2}{|c|}{} & Learning Strategy \\
\hline \multirow{3}{*}{ Autonomy } & Pearson Correlation & $.775^{* *}$ \\
\cline { 2 - 3 } & Sig. (2-tailed) & .000 \\
\cline { 2 - 3 } & $\mathrm{N}$ & $\mathbf{1 4 0}$ \\
\hline \multicolumn{2}{|c|}{$* *$ Correlation is significant at the 0.01 level (2-tailed). } \\
\hline
\end{tabular}

Moreover, for further analysis, correlations between different components of VLSQ and AU were calculated (Table 16).

Table 16: Correlations between each Component of VLSQ and Autonomy

\begin{tabular}{|c|c|c|}
\hline \multicolumn{3}{|c|}{ Correlations } \\
\hline VLSQ & & AUTONOMY \\
\hline \multirow{3}{*}{ Metacognitive } & Pearson Correlation & $.745^{* *}$ \\
\hline & Sig. (2-tailed) & .000 \\
\hline & $\mathrm{N}$ & 100 \\
\hline \multirow{3}{*}{ Cognitive } & Pearson Correlation & $.507^{* *}$ \\
\hline & Sig. (2-tailed) & .002 \\
\hline & $\mathrm{N}$ & 100 \\
\hline \multirow{3}{*}{ Memory } & Pearson Correlation & $.428^{* *}$ \\
\hline & Sig. (2-tailed) & .000 \\
\hline & $\mathrm{N}$ & 100 \\
\hline \multirow{3}{*}{ Determination } & Pearson Correlation & $.401^{* *}$ \\
\hline & Sig. (2-tailed) & .000 \\
\hline & $\mathrm{N}$ & 100 \\
\hline \multirow{3}{*}{ Social } & Pearson Correlation & $.372^{* *}$ \\
\hline & Sig. (2-tailed) & .006 \\
\hline & $\mathrm{N}$ & 100 \\
\hline
\end{tabular}

This table reveals that AU is correlated positively and significantly with all of the components of VLSQ.

\section{The Fifth Research Question}

A Spearman's correlation was run to probe any significant relationship between VLS of EFL learners and their PT. The results $\left(r_{138}=-.17, p=.04<.05\right.$, it represents a weak effect size) indicate a weak relationship between the two variables (Table 17). Thus, there was not any significant relationship between EFL learners' VLS and PT.

Table 17: Correlation between Vocabulary Learning Strategy and Personality Type

\begin{tabular}{|c|c|c|}
\hline \multicolumn{2}{|c|}{} & $\begin{array}{c}\text { Vocabulary } \\
\text { learning strategy }\end{array}$ \\
\hline \multirow{3}{*}{ Personality Type } & Pearson Correlation & $-.174^{*}$ \\
\cline { 2 - 3 } & Sig. (2-tailed) & .040 \\
\cline { 2 - 3 } & $\mathrm{N}$ & $\mathbf{1 4 0}$ \\
\hline \multicolumn{2}{|c|}{$* *$ Correlation is significant at the 0.01 level (2-tailed). } \\
\hline
\end{tabular}

\section{The Sixth Research Question}

A Spearman correlation was run to probe any significant relationship between CT ability of EFL learners and their PT. Before commenting on the findings it should be mentioned that the relationship between the two variables is almost zero. As displayed in Figure 6, the spread of the dots shows a low and non-linear correlation between the two variables. The rising-and-falling shape of the dots supports the non-linearity of the variables.

The results of the Spearman's correlation $\left(r_{138}=-.19, p=.04<.05\right.$, it represents a weak effect size) indicated a weak relationship between the two variables (Table 18). Thus, there was not any significant relationship between EFL learners' CT and PT, due to the low correlation and non-linearity of the relationship.

Table 18: Correlation between Critical Thinking and Personality Type

\begin{tabular}{|l|c|c|}
\hline \multicolumn{2}{|c|}{} & Critical Thinking \\
\hline \multirow{3}{*}{ Personality Type } & Pearson Correlation & -.195 \\
\cline { 2 - 3 } & Sig. (2-tailed) & .040 \\
\cline { 2 - 3 } & $\mathbf{N}$ & 140 \\
\hline \multicolumn{2}{|c|}{$*$. Correlation is significant at the 0.01 level (2-tailed). } \\
\hline
\end{tabular}




\section{The Seventh Research Question}

A linear regression was run to inspect the predictionof EFL learners' VLS by using their AU, PT, and CT. As displayed in Figure 11, the regression model is linear. The cluster of dots around the diagonal suggests linear relationships between the variables.

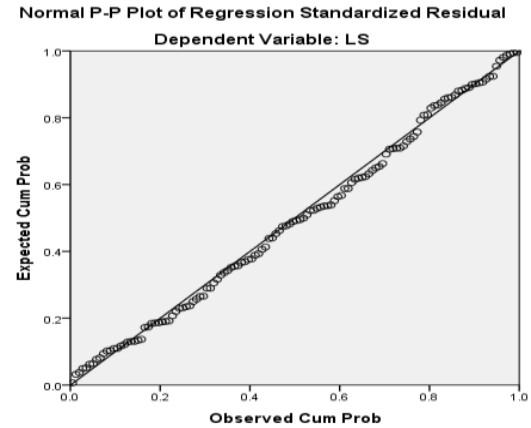

Figure 11: Normal P-P Plot: Linearity of Regression Model

The regression model converged in two steps (Table 4.16). AU was the best predictor of VLS $\left(\mathrm{R}=.24, \mathrm{R}^{2}=\right.$ .068 ). That is to say that AU can predict about 6.8 percent of students' learning strategies. CTwas the second best predictor of VLS $\left(\mathrm{R}=.32, \mathrm{R}^{2}=.10\right)$. That is to say the regression model including CT and AU can predict about 10 percent of students' VLS.

Table 19: Regression Output, Model Summary

\begin{tabular}{|c|c|c|c|c|}
\hline Model & $\mathbf{R}$ & R Square & Adjusted R Square & $\begin{array}{c}\text { Std. Error of the } \\
\text { Estimate }\end{array}$ \\
\hline 1 & $.261^{\text {a }}$ & .068 & .061 & .520 \\
\hline 2 & $.316^{\text {b }}$ & .100 & .086 & .513 \\
\hline a. Predictors: (Constant), Autonomy \\
\hline \\
b. Predictors: (Constant), Critical Thinking \\
c. Dependent Variable: Vocabulary Learning Strategies
\end{tabular}

The results of the ANOVA test $\left(\mathrm{F}_{2,127}=7.03, p=.001, \omega^{2}=.08\right.$ it represents moderate to large effect size $)$ indicated that the regression model enjoys statistical significance (Table 20).

Table 20: Regression Output, ANOVA

\begin{tabular}{|l|c|c|c|c|c|c|}
\hline \multicolumn{2}{|c|}{ Model } & Sum of Squares & df & Mean Square & F & Sig. \\
\hline \multirow{3}{*}{1} & Regression & 2.539 & 1 & 2.539 & 9.388 & $.003^{\text {b }}$ \\
\cline { 2 - 7 } & Residual & 34.618 & 138 & .270 & & \\
\cline { 2 - 7 } & Total & 37.157 & 139 & & & \\
\hline \multirow{3}{*}{2} & Regression & 3.707 & 2 & 1.853 & 7.037 & $.001^{\text {c }}$ \\
\cline { 2 - 7 } & Residual & 33.450 & 137 & .263 & & \\
\cline { 2 - 7 } & Total & 37.157 & 139 & & & \\
\hline \\
a. Dependent Variable: Language Learning Strategies \\
b. Predictors: (Constant), Emotional Intelligence \\
c. Predictors: (Constant), EMI, Tolerance of Ambiguity
\end{tabular}

Based on the obtained results, it can be concluded that there is a difference among EFL learners' CT, PT, and AU in predicting their use of language learning strategies. More specifically, CT and AU can significantly predict students' VLS while PT does not contribute significantly to the regression model.

\section{Construct Validity}

A factor analysis through the varimax rotation was carried out to probe the underlying constructs of the CT, AU, and VLS. As displayed in Table 21, the CT, AU, and VLS items load on a single factor.

Table 21: Factor Loadings

\begin{tabular}{|c|c|}
\hline & Component \\
\cline { 2 - 2 } & 1 \\
\hline $\begin{array}{c}\text { vocabulary Learning } \\
\text { Strategies }\end{array}$ & .752 \\
\hline Autonomy & .683 \\
\hline Critical Thinking & .615 \\
\hline
\end{tabular}




\section{Discussion}

The current study attempted to investigate the possible relationships among EFL learners' CR, AU, PT, and VLS. Based on the pertinent data analyses carried out, the researchers observed that there is a significant relationship among the abovementioned variables. It was observed that a statistically significant relationship exists between EFL learners' AU and CT $(r=0.78)$. This finding was in line with the results of another study conducted by Zaker (2013), where a significant, though smaller relationship was observed between CT and AU $(r=0.736)$. This study also revealed that a positive and significant correlation exists between EFL learners' CT and overall use of VLS $(r=0.72)$, and EFL learners' AU and overall use of VLS $(r=0.77)$. Moreover, significant correlations were observed among the components of VLSQ and CTbeside significant correlations among the components of VLSQ and AU.

According to the results of the regression model which was converged in two steps (Table 19), AU was the best predictor of VLS $\left(\mathrm{R}=.26, \mathrm{R}^{2}=.068\right)$ and CT is the second best predictor of VLS $\left(\mathrm{R}=.32, \mathrm{R}^{2}=.10\right)$. This point indicates that CT and AU can significantly contribute to the degree of VLS among EFL learners. It was systematically confirmed that AU makes the largest unique contribution to explaining VLS among EFL learners. This point seems to be in line with Dickinson's (1992) arguments where he states that those students who depend on themselves in learning, have a higher chance to internalize vocabularies and, as a result, to succeed academically.In general, the results of the present study revealed that when there is variance in any of $\mathrm{CT}, \mathrm{AU}$, or VLSthere also exists variance in the two other variable(s). Put simplistically, the three variables are closely and significantly interconnected. Furthermore, between AU and CT, AU is a better predictor of VLS among EFL learners, as observed in this sample.The findings were also supported by the findings of Abbasi (2012) who found strong relationship amongCT, overall use of VLS, and AU.

In addition, according to the results of the present study, no statistically significant relationship was found between EFL learners'PT and their AU, which is opposed to the results of previous related studies (Herbeson\& Frances, 1990; Hudson, 2001) indicating that there is a significant correlation between PT and selfdirected (autonomous) learning.A justifiable explanation for the inconsistent findings of these two personal variablesis that they do not operate uniformly for all students in all contexts. Since, a learner who is highly autonomous in one circumstance may be not autonomous at all in another. Benson (2001) described learner AU as a multidimensional capacity that will take different forms for different individuals and even for the same individual in different contexts or at different times. Moreover, according to Pennycook (1997) cultural factors affect the notion of AU and autonomous individual.

Also, the inconsistent findings can be interpreted with respect to this reason that personality preferences, as set out in the MBTI, give no indication of student maturity, motivation, or of situational factors (Carrell, et al., 1996). Since no statistically significant relationship was found between EFL learners' PTs and their overall use of VLS, it can be concluded that both variables do not have a same channel to direct their influence in common. This conclusion ran counter to the statement of Williams and Burden (1997) that, "It is undoubtedly true that learners bring many individual characteristics to the learning process which will affect both the way in which they learn and the outcomes of that process" (p. 88).

The results of the present study were also opposed to a number of previous related studies (HosseiniNaveh, Kafipour, \&Soltani, 2011; Marin, 2005) whose correlational analyses revealed a strong relationship between extroversion tendency and use of VLS. However, there is another study by Sarani and VahedAhmadian (2011) reported no significant correlation between introverts and extroverts in the overall use of VLS. Moreover, according to some large-scale studies investigating VLS in Asian countries (Fan, 2003; Gu\& Johnson, 1996; Schmitt, 1997), culture influences students' selection of VLS.

The findings of this study may have implications for EFL teachers. According to Scharle and Szabo (2000), it is a fact that the class time for vocabulary is extremely limited compared with the enormous number of vocabulary items that learners need to acquire. Therefore, studying vocabulary on their own is a must for all learners. The best preparation the teacher can provide is to help them become more autonomous.EFL teachers are also suggested to inform EFL learners of the ways through which AU, CT, and VLS can contribute to learning more independently, reliably, lastingly, and effectively.Moreover, the teacher can administer a questionnaire at the beginning of a course to inspect learners' preference of using VLS. Because of the differences among learners, the teacher should provide a wide range of VLS in order to meet the needs and expectations of the students.

Due to the fact that language learning is a multidimensional phenomenon, not only language teachers, but also language learners are required to play their role properly in order to facilitate and optimize this complicated process. Therefore, results of the current study may have implications for language learners.Students who think and work strategically are more motivated to learn and have a higher sense of selfefficacy or confidence in their own learning ability (Benson, 2003; Dam, 1995; Dickinson, 1992; Holec, 1981; Little, 1991). Some benefits of using "strategy training" have been ascribed by Walters and Bozkurt (2009, p. 
405), among them "enhancing learner autonomy" is the most important one. Thus, including vocabulary learning strategies in a curriculum can help students become more autonomous learners.

Syllabus designers as providers of a great portion of the language learning setting, have a fundamental role to make the process easier. They should take into consideration learners' individual differences, especially their PTs, their CT ability, their AU level, and their VLS preference in their courses which can result in intellectual, active learners. When relevant training hints or motives are inserted in appropriate parts of a course book, teachers are provided with a powerful device to optimize language learning activities, and learners can benefit from a more detailed EFL context. According to Ellis (1994), researchers classify the good learner as someone who makes use of language learning strategies usefully, who controls themselves, and who is familiar with learning process. Textbook writers should, therefore, equip learners with a larger repertoire of VLS. This can help students to be more responsible for their own learning and to be more familiar with the learning process.

\section{References}

[1]. Astleitner, H. (2002). Teaching critical thinking online. Journal of instructional psychology, 29(2), 53-77.

[2]. Bahri, H. (2003). The relationship between teaching styles and personality type of the Iranian EFL teachers(Unpublished master's thesis).TarbiatModares University, Tehran, Iran.

[3]. Benson, P. (2001). Teaching and Researching Autonomy in Language Learning. London: Longman.

[4]. Benson, P. (2003). Learner autonomy in the classroom.In D. Nunan(Ed.),Practical English Language Teaching (pp. 289-308). New York: McGraw Hill.

[5]. Carrell, M. R., Elbert, N.F., Hatfield, R.D., Grobler, P.A., Marx, M., \& van der Schyf, S. (1996).Psychometric testing and assessment techniques.E-Journal.Retrieved April 11, 2013, from: http://www.academon.com/essay/psychometric-testing-andassessment-techniques-2198.

[6]. Catalan, R. (2003). Sex differences in L2 vocabulary learning strategies. International Journal of Applied Linguistics, 13(1), 54-77.

[7]. Connolly, M. (2000). What we think we know about critical thinking. CELE Journal, 8, Retrieved April 20, 2003, fromhttp://www.asia-u.ac.jp/english/cele/articles/ Connolly Critical-Thinking.htm

[8]. Cook, V. (2001). Second language learning and leaching (3 $3^{\text {rd }}$ ed.). London: Arnold.

[9]. Cotteral, S (1995).Developing a course strategy for learner autonomy.ELT Journal, Vol. 49/3, 1995.

[10]. Dam, L. (1995). Learner Autonomy 3: From Theory to Classroom Practice. Dublin: Authentik.

[11]. Davidson, B. (1998). A case for critical thinking in the English language classroom.TESOL Quarterly, 32, $119-123$.

[12]. Davidson, B., \& Dunham, R. (1997). Assessing EFL student progress in critical thinking with the Ennis-Weir Critical Thinking Essay Test. JALT Journal, 19(1), 43-57.

[13]. Decarrico, J. S. (2001). Vocabulary learning and teaching. In M. Celce-Murcia (Ed.), Teaching English as a second or foreign language (3rd ed.) (pp. 285-299). Boston: Heinle\&Heinle.

[14]. Dickinson, L. (1992). Learner autonomy: Learner training for language learning. Dublin: Authentik.

[15]. Ehrman, M. E. (1996). The type differentiation indicator and adult foreign language learning success.Journal of Psychological type, 30(1), 10-29.

[16]. Ellis, R. (1994). The study of second language acquisition. Oxford: Oxford University Press.

[17]. Fahim, M. \&Sheikhy B., R. (2011).Critical thinking ability and autonomy of Iranian EFL learners.American Journal of Scientific Research, Issue 29, 59-72.

[18]. Fahim, M. \&Komijani, A. (2010).Critical Thinking Ability, L2 Vocabulary Knowledge, and L2 Vocabulary Learning Strategies.Journal of English Studies, 1(1), 23-38.

[19]. Fan, M. Y. (2003). Frequency of use, perceived, usefulness, and actual usefulness of vocabulary strategies: A study of Hong Kong learners. The Modern Language Journal, 87(2), 222, 241.

[20]. Flower, J. (2000). Start building your vocabulary. Hove: Language Teaching.

[21]. Gu, Y. P., \& Johnson, R. K. (1996). Vocabulary learning strategies and language learning outcomes. Language learning, 46(4), 643679.

[22]. Hall, B. T. (2000). Issues in teaching vocabulary. Available: http://www.suite101 com.htm

[23]. Hatch, E. \& Brown, C. (1995).Vocabulary, semantics, and language education. New York: Cambridge University Press.

[24]. Hedge, T. (2000). Teaching and learning in the language classroom. Oxford: Oxford University Press.

[25]. Herbeson, D. \& Frances, E. (1990).Personality type and self-directed learning. New Directions for Teaching and Learning, 80, 3964.

[26]. Holec, H. (1981). Autonomy and Foreign Language Learning. Oxford: Pergamon.

[27]. Honey, P. (2000).CT questionnaire. Retrieved October 8, 2009, from Peter Honey Learning Website:http:// www.Peter Honey Publications.com

[28]. HosseiniNaveh, M.,Kafipour, R. \&Soltani, R. (2011). The relationship among extraversion tendency, vocabulary learning strategies, and reading comprehension of EFL undergraduates in Kerman province. The Modern Language Journal, 3(2), 13-33.

[29]. Hudson, J. (2001). Predicting self-directed learning from personality type.The Modern Language Journal, 62(5), 36-72.

[30]. Kojic-Sabo, I., \&Lightbown, P. M. (1999).Students' approaches to vocabulary learning and their relationship to success. Modern Language Journal, 83(2), 176-192.

[31]. Ku, Y. L. K. (2009). Assessing students' critical thinking performance: Urging for measurements using multi-response format. Thinking Skills and Creativity, 4, 70-76.

[32]. Little, D. (1991).Learner Autonomy 1: Definitions, Issues and Problems. Dublin: Authentik.

[33]. Little, D (1995). Learning as dialogue: The dependence of learner autonomy on teacher autonomy. System,23(2). 175-182.

[34]. Maley, A. (1986). Series editors' preface.In J. Morgan, and M. Rinvolucri (Eds.), Vocabulary.Oxford: Oxford University Press.

[35]. Marin, A. (2005). Extraversion and the use of vocabulary learning strategies among University EFL students in Mexico.The Modern Language Journal, 3(2), 15-33.

[36]. McCarthy, (1988). Vocabulary and Language Teaching. New York: Longman.

[37]. Meara, P. (1980). Vocabulary acquisition: A neglected aspect of language learning. Language Teaching and Linguistics, 13(4): 221246 . 
[38]. Mohammadi, S. (2009).The relationship between personality type of Iranian EFL learners and their familiarity with certain speech acts strategies (Unpublished master's thesis). Islamic Azad University, Science and Research Branch, Tehran, Iran.

[39]. Myers, LB., \&McCaulley, M.H. (1985).Manual: A guide to the development and use of the Myers-Briggs Type Indicator. Palo Alto, CA: Consulting Psychologists Press.

[40]. Naeini J. (2005). The effects of collaborative learning on critical thinking of Iranian EFL learners(Unpublished master's thesis).Islamic Azad University at Central Tehran, Iran.

[41]. Nation, I. S. P. (2001).Learning vocabulary in another language. Cambridge: Cambridge University Press.

[42]. Nation, P. (2004). Evaluating your vocabulary programme. In Y. Leung \& Y. Chen (Eds.), Selected papers from the thirteenth international symposium on English teaching (pp. 91-97). Taipei, Taiwan: The Crane.

[43]. Nation, P.,\&Meara, P. (2002). Vocabulary. In N. Schmitt (Ed.), An introduction to applied linguistics (pp. 35-54). London: Arnold.

[44]. O'Malley, J. M., and Chamot, A. U. (1990).Learning strategies in second language acquisition. Cambridge: Cambridge University Press.

[45]. O'Malley, J. M. and Chamot, A. U. (1996).Learning strategies in second language acquisition. U.S.A: Cambridge University Press.

[46]. Oxford, R. L. (1990). Language learning strategies: What every teacher should know. Boston: Heinle\&Heinle.

[47]. Oxford, R. L. (2001). Language learning styles and strategies.In M. Celce-Murcia (Ed.), Teaching English as second or foreign language (pp. 359-366). Boston, MA: Heinle\&Heinle.

[48]. Oxford, R., \&Crookall, D. (1990). Vocabulary learning: A critical analysis of techniques. TESL Canada Journal, 7(2), 9-30.

[49]. Paul, R. (1990). Critical thinking: What every person needs to survive in a rapidly changing word. Retrived November 5, 2007 from http://serc.carleton.edu/resources/867.html.

[50]. Paul, R., \& Elder, L. (2002).Critical thinking concepts and tools.Retrieved from November 5, 2007 from http://www.colorado.edu /cources/ 4800armstrong/ critical \%20 thinking.pdf.

[51]. Pennycook, A. (1997). Cultural alternatives and autonomy.In P. Benson and P. Voller (Eds.), Autonomy and independence in language learning (pp.35-53). London: Longman.

[52]. Pressley, M. (2000). Comprehension instruction: What makes sense now, what might make sense soon? Handbook of Reading research, 2, 6, 23-38

[53]. Pressley, M., Brown, R., El-Dinary, P.B., \&Afflerbach, P. (1995). The comprehension instruction that students need: Instruction fostering constructively responsive reading. Learning Disabilities Research and Practice, 10, 215-224

[54]. Read, J. (2000). Assessing vocabulary. Cambridge: Cambridge University Press.

[55]. Rubin, J. (1987). Learner strategies: Theoretical assumptions, research history, and typology. In A. Wenden, \& J. Rubin (Eds.), Learner strategies in language learning. (pp. 15-30). London: Prentice Hall International.

[56]. Sarani, A. \&VahedAhmadian, B. (2011).The relationship between EFL extroverts and introverts and their overall use of vocabulary learning strategies. World Englishes, 22(1), 55-66.

[57]. Scharle, A. \&Szabó, A. (2000).Learner Autonomy.A Guide to Developing Learner Responsibility. Cambridge: Cambridge University Press.

[58]. Schmitt, N. (1997). Vocabulary learning strategies. In N. Schmitt \& McCarthy (Eds.), Vocabulary: description, acquisition and pedagogy (pp.199-228). Cambridge: Cambridge University Press.

[59]. Schmitt, N. (2000). Vocabulary in language teaching. Cambridge: Cambridge University Press.

[60]. Sharp, A. (2004). Language learning and awareness of personality type in Chinese settings. Asian EFL Journal, 6(2), 1-13.

[61]. Shen, W. W. (2004). Does the practice of English vocabulary learning strategies follow theories? In Y. Leung \& Y. Chen (Eds.), Selected papers from the thirteenth international symposium on English teaching (pp. 91-97). Taipei. Taiwan: The Crane.

[62]. Singleton, D. (1999).Exploring the second language mental lexicon. Cambridge: Cambridge University Press.

[63]. Spratt, M., Humphreys, G. \& Chan, V. (2002). Autonomy and motivation. Which comes first? Language Teaching Research, 6(3), $245-266$.

[64]. Stoffer, I. (1995). University foreign language students' choice of vocabulary learning strategies as related to individual difference variables (Unpublished doctoral dissertation). The University of Alabama, USA.

[65]. Thornbury, S. (2002).How to teach vocabulary. Malaysia: Longman-Pearson Educational.

[66]. Tsuchida, M. (2002).The learning strategies: Helping students learn how to learn. (ERIC Document Reproduction Service No. ED463655).

[67]. Vogt, W. P. (2007). Quantitative research methods for professionals. New York: Pearson Education.

[68]. Wagner, R. K. (1997). Intelligence, training, and employment. American Psychologist, 52, 1059-1069.

[69]. Walters, J. and Bozkurt, N. (2009). The effect of keeping vocabulary notebooks on vocabulary acquisition.Language Teaching Research, 13(4), 403-423.

[70]. Williams, M., and Burden, R.L. (1997). Psychology for language teacher: A social constructivist approach. Cambridge: Cambridge University Press.

[71]. Zaker, A. (2013). The relationship among EFL learners' creativity, critical thinking, and autonomy (Unpublished master's thesis).Islamic Azad University at Central Tehran, Iran. 